\title{
AS EXPOSIÇÕES DE ARTE E O DEBATE CULTURAL
}

Paulo Roberto de Oliveira Reis*

I

No contexto do "Simpósio Nacional de Tecnologia e Sociedade" e dentro da mesa redonda que se intitula "Cultura, Espaço e Interação" escolhi para tema de minha apresentação "As exposições de arte e o debate cultural". Parti do princípio de que a discussão artística ganha o espaço público através das exposições de arte. Caracterizo as exposições de arte como espaços de interação entendida como participação semântica ou sensorial, do público mais amplo ou especializado. Por discussões artísticas eu entendo também as discussões que cortam transversalmente o mundo da cultura. E, por último, enfocarei mais especificamente a atuação do curador Paulo Herkenhoff e seu projeto de fundamentação do debate artístico em algumas questões de base da cultura brasileira.

De que maneira as exposições de arte transformam-se em espaços de interação com o espectador? As exposições de arte como espaço civil de mostra e apreciação de artes plásticas originam-se no séc. XVII ${ }^{1}$. Ligadas, num primeiro momento, à produção artística das academias de arte na

* Mestre em História Social da Cultura pela Pontifícia Universidade Católica do Rio de Janeiro e doutor em História pela Universidade Federal do Paraná. Professor da Universidade Federal do Paraná. (paulo_reis@uol.com.br)

1 Ver Crow, Thomas. Painters and public life in Eighteenth-Century Paris. New Haven: Yale University Press, 2000. 
França, posteriormente, no séc. XVIII, passam a acontecer nos salões do Palácio do Louvre, ganhando então a denominação de Salões. Desde o princípio, os salões foram pensados como espaços de crítica aberta, o que fica evidente nas proposições de seus catálogos e textos à crítica ampla tanto do "connaisseur" quanto do público leigo ${ }^{2}$.

As exposições ganharam renovada importância no final do séc. XIX ao afirmarem a modernidade visual em franca oposição à arte acadêmica. Os salões de recusados representaram o posicionamento crítico dos artistas junto ao público ao mostrarem a nova visualidade. Os salões também foram o porta-voz das primeiras vanguardas do séc. $\mathrm{XX}^{3}$. Inseridas como uma estratégia de visibilidade, momento privilegiado de contato com o público mais geral e debate de idéias, as exposições acompanharam a movimentação do Futurismo, ao percorrer diversas cidades européias, do Expressionismo, ao percorrer diversas cidades alemãs e das movimentações do Dadaísmo e Surrealismo, entre outras.

A própria exposição, como espaço simbólico e fisico, foi sendo transformada para se adequar às novas formas e linguagens artísticas. Assim, exposições como Sonderbund, na Alemanha (1912), e Armory Show, nos Estados Unidos (1913), propuseram uma leitura da modernidade e de seus antecedentes, numa forma moderna de apresentação e visualização dos trabalhos. Esta forma moderna muitas vezes chocava-se com a ordem pública e a lei, como atestam o processo político recebido pelos dadaístas

2 O filósofo francês Denis Diderot foi um entusiasta das exposições do Salão da Academia Francesa e as via como mais uma possibilidade de educação da civilidade no homem iluminista. Para ele as exposições públicas tinham um estatuto de vital importância pois que através delas se procurava em todos os estados da sociedade, particularmente aos homens de gosto, um élan útil e uma recreação agradável (Diderot, Denis apud Hegewish, Katharina in "L'Art de l'exposition”, Éditions du Regard, Paris, 1998, p. 18).

3 Ver Altschuler, Bruce. The Avant-garde in exhibition. Berkeley: University of Califórnia Press, 1994. 
alemães na exposição "Primeira Feira Internacional Dadaísta" em Berlim (1920) e o quase fechamento pela polícia da "Exposição Internacional do Surrealismo" em Paris (1938).

As exposições de arte configuram-se como o espaço de ligação entre artistas e público e, de maneira mais ampla, entre novas proposições visuais concepções de arte e a sociedade. Exposições representam o 'locus' entre as novas proposições artísticas e o público. No Brasil, as exposições de arte configuraram a história cultural do país desde as exposições da Academia Imperial de Belas Artes no séc. XIX. No início do séc. XX, a modernidade foi pensada e experimentada nas exposições de Lasar Segall (1913) e Anita Malfatti (1917), passando pela Semana de Arte Moderna (1922) até o chamado Salão Revolucionário (1931), organizado por Lúcio Costa. Uma nova concepção radical de modernidade esteve presente nestas exposições e nem sempre sua aceitação se deu de maneira acomodada, como no episódio da crítica de Monteiro Lobato à exposição de Malfatti.

II

Durante o séc. XX, as exposições de arte deram visibilidade à produção artística mais experimental e acompanharam também o grande debate da cultura no Brasil. Na criação dos museus de arte moderna, em fins dos anos 40, a tradição moderna brasileira começou a ser construída com inúmeras retrospectivas de $\operatorname{artistas}^{4}$. Nos anos 50 algumas exposições apresentaram as novas questões do abstracionismo geométrico em sintonia com o momento desenvolvimentista do país. Nos anos 60 as exposições adquiriram uma importante função, ao servirem como resistência artística ao regime militar instaurado com o golpe de 1964. Nas décadas de 70, 80

4 Ver Lourenço, Maria Cecília França. Os museus acolhem moderno. São Paulo: EDUSP, 1999. 
e 90 e anos 2000, algumas exposições encarnaram o espírito da época, como "Do Corpo à Terra" (Belo Horizonte/1970) e o sufoco da ditadura pós AI-5, as edições da "Jovem arte contemporânea" (MAC-SP-anos 70) e a possibilidade de experimentação artística em meio ao regime militar, “Como vai você Geração 80?” (Parque Lage/RJ-1984) e o período de abertura política e sua reverberação nas artes visuais. Mais recentemente, algumas exposições da Bienal de São Paulo, Mostras da Gravura de Curitiba e Panorama da Arte Brasileira, entre tantas, trouxeram discussões artísticas em conformidade ao momento social e político.

$\mathrm{Na}$ dinâmica das exposições, um elemento adquire um papel determinante no agenciamento das proposições artísticas - o curador de exposições. Termo surgido muito recentemente no circuito brasileiro ${ }^{5}$, o curador designa aquele profissional que organiza exposições, pode ou não trabalhar numa instituição de arte e, originalmente, possuía a missão de preservar e cuidar de um acervo de museu. Na organização das exposições, o curador pode contar com acervos artísticos de museus ou particulares, ter como espaço uma instituição de arte ou espaço adaptado, focar a obra de um determinado artista ou um conjunto de artistas. Porém sempre realizará uma leitura própria dos trabalhos expostos, sugerirá um percurso de exposição, escreverá um texto crítico e apresentará um problema artístico específico. E é na atuação do curador que se percebe mais claramente de que maneira a exposição torna-se um espaço de debate artístico e cultural com o público.

A atuação do curador Paulo Herkenhoff ${ }^{6}$ caracteriza-se como uma das mais importantes no circuito artístico brasileiro e internacional e tem

5 A XVI Bienal de São Paulo de 1981 foi a primeira a ter curadoria, realizada por Walter Zanini.

6 Nasceu no ano de 1949 em Cachoeiro do Itapemerim-ES. 
por características uma formulação dinâmica entre as questões artísticas e as discussões culturais da maior relevância para o país. Sua atuação, como artista, inicia-se juntamente ao grupo carioca que reunia Fernando Cocchiarale, Letícia Parente, Ana Vitória Mussi, Anna Bella Geiger, entre outros, na experimentação da vídeo-arte no Brasil durante a década de 70 . Sua posterior atuação profissional foi realizada como diretor do Museu de Arte Moderna do Rio de Janeiro, do Instituto Nacional de Artes Plásticas (FUNARTE) e atualmente do Museu Nacional de Belas Artes. Foi curador da $23^{\mathrm{a}}$ e $24^{\mathrm{a}}$ edições da Bienal Internacional de Arte de São Paulo, curador de três Mostras da Gravura de Curitiba e também curador adjunto do Museu de Arte Moderna de Nova York (MoMA).

Textos construídos como grandes mosaicos são a característica de Herkenhoff. Aliam-se o rigor formal do conhecimento da arte brasileira (ou internacional) a uma liberdade conceitual que, em suas miríades de entrelaçamentos entre fatos e leituras, mostram a perquirição mais densa do autor. Muitas vezes seus textos assemelham-se a projetos de curadorias ${ }^{7}$ ao juntar referências de artistas e obras a questões conceituais mais teóricas da arte e da sociedade. Um dos textos mais intrincados de Paulo Herkenhoff e que parece apontar muitas de suas preocupações futuras foi "Glossário incompleto de fontes da arte latino-americana" ${ }^{8}$, publicado em 1993. O texto, escrito em forma de dicionário, apresenta em verbetes organizados por ordem alfabética, algumas questões de base para pensar

7 E em alguns casos são, pois é o que parece acontecer com o texto "Tiempo fracturado" (Jiménez, José e Castro, Fernando - orgs. Horizontes del arte latinoamericano. Madri: ed. Tecnos, 1999) e a posterior exposição "Tempo" (Museu de Arte Moderna de Nova York, 2002).

8 Este texto ("Incomplete glossary of sources of Latin American art") acompanhou o catálogo “Cartographies” (Winnipeg Art Gallery, Canadá, 1993). A exposição teve curadoria de Ivo Mesquita e propunha um outro olhar crítico para a produção artística da América espanhola e portuguesa. $\mathrm{O}$ texto do curador, neste catálogo, representa uma tomada de posição ética e política sobre a operação curatorial. 
e problematizar preconceitos sobre a produção artística da América do Sul e Central. Verbetes como África, Canibalismo, Banana, Barroco, Carnaval, Cegueira, Censura, Cocaína, Construtivismo, Corpo, Departamento de Estado Norte-Americano, Ditadura, Loucura e Tempo, entre tantas, levantam questões da colonização da América espanhola e portuguesa, sua formação cultural, posição no mundo contemporâneo, mitos, projeções do europeu e projetos nacionais.

O texto “Tempo fraturado" ${ }^{9}$, publicado em 1999, aprofunda algumas condições e contradições da arte na América Latina, dada na discussão de suas concepções e construções de temporalidades. Questionando a idéia de uma América Latina como "terra do amanhã" ${ }^{10}$, na qual se viveria um tempo projetivo sempre em direção ao futuro e a uma obliteração do presente (e da história), as diversas colocações de tempo margeiam as discussões artísticas da construção da arte no continente. Outras concepções de tempo perpassam o texto, num esforço de demarcar territórios de discussão, crítica e atuação artística. Seja a narrativa histórica ocidental que deixa de lado a arte dos países da América portuguesa e espanhola ou no ânimo de artistas como agentes da história ao fazerem convergir suas discussões artísticas para o campo político, social e ético ${ }^{11}$, o texto traça linhas de força da cultura latino-americana.

A estrutura de análise teórica dos textos, sua interconexão entre fatos artísticos e fatos sociais, a narrativa construída sobre obras e poéticas artísticas e uma trama de referências teóricas, são orientações também de

9 "Tiempo fracturado". Horizontes del arte latinoamericano.

10 "Tierra de mañana”, p. 141.

${ }^{11}$ A frase traz uma citação do texto "Esquema geral da nova objetividade" (1967) de Hélio Oiticica. No texto de Herkenhoff isto é exemplificado pelo livro "Antiestética" (1965) de Luis Felipe Noé e na poética de Cildo Meireles. 
muitas das curadorias de Paulo Herkenhoff. Situarei quatro curadorias de Herkenhoff, "Bienal de São Paulo” (São Paulo-1998), "Vigiar e punir” (Curitiba-2000), “Trajetória da Luz” (São Paulo-2001), e “Tomie Ohtake e a trama espiritual da arte brasileira” (São Paulo e Curitiba-2004), com a intenção deixar claros alguns de seus agenciamentos artísticos e debate cultural, numa perspectiva de reflexão da exposição como arena de discussões com o público.

A XXIV Bienal de São Paulo (1998), também chamada a Bienal da Antropofagia, teve curadoria de Paulo Herkenhoff e curadoria adjunta de Adriano Pedrosa. Dentre quatro "momentos densos" da História da Arte Brasileira, barroco, modernismo, neoconcretismo e anos 60/70, o curador escolheu a antropofagia como perspectiva história para a Bienal de São Paulo ${ }^{12}$. Ao destacar a intenção de construir o Núcleo Histórico da Bienal de maneira não-eurocêntrica, a escolha da antropofagia privilegiou uma discussão de base da cultura brasileira, a dependência cultural ${ }^{13}$. Em sua postura de ordenar toda a Bienal pelo foco da antropofagia, Herkenhoff tomou o partido dos intelectuais que desvinculam a dependência cultural à dependência econômica. Um texto de base, citado pelo curador para o entendimento da antropofagia, foi "Da razão antropofágica: diálogo e diferença na cultura brasileira”, de Haroldo de Campos ${ }^{14}$.

Dividida entre as exposições propriamente ditas, os quatro livroscatálogos e um território digital de web arte ${ }^{15}$, a Bienal de certa maneira

12 Ver catálogo XXIV Bienal de São Paulo - núcleo histórico: Antropofagia e histórias de canibalismos. São Paulo: Fundação Bienal de São Paulo, 1998.

${ }^{13}$ Debate travado a partir de final dos anos 60 , a dependência cultural, vista em relação à dependência econômica, foi discutida por grandes intelectuais como Roberto Schwarz, Ferreira Gullar, Haroldo de Campos e Silviano Santiago.

${ }_{14}$ Campos, Haroldo. Metalinguagem e outras metas. São Paulo: Perspectiva, 1992.

${ }^{15}$ Ver dissertação "XXIV Bienal de São Paulo: a hipermídia como metáfora" de Simone Landal, defendida em 2005 no Curso de Pós-Graduação em Comunicação e Linguagens, na Universidade Tuiuti do Paraná. 
inverteu uma polaridade ideológica dentro da própria história das Bienais. Ao tomar como ponto de partida a antropofagia, operação inaugurada com o Manifesto Antropófago, de Oswald de Andrade, em 1928, constrói-se uma história da arte e da cultura dada a partir da periferia (Brasil) e não a partir do centro (Europa ou Estados Unidos).

A exposição "Vigiar e punir" foi uma das exposições da XII Mostra da Gravura de Curitiba. Sua denominação foi uma apropriação do título do livro de Michel Foucault e teve aí sua base conceitual. Três artistas do séc. XVII, XVIII e XIX foram os fundamentos históricos para a exposição ${ }^{16}$. Dos artistas Jacques Callot, Piranesi e Goya, foram mostradas gravuras que representavam o horror da guerra, o Estado violento e a irracionalidade. À partir deles teceu-se uma narrativa de obras brasileiras que colocavam-se como "momentos éticos" ${ }^{17}$ na arte brasileira.

A crônica "Mineirinho", de Clarice Lispector, disposta pelo espaço expositivo, apontava o estado policial e violento brasileiro em sua crise ética. Herkenhoff colocava em discussão certas produções artísticas que dialogavam com questões como os estados modernos e regimes autoritários. $\mathrm{O}$ regime militar autoritário, o estado policial que favorece as elites ou a memória e o esquecimento da barbárie social eram algumas das questões que atravessavam as obras de Iberê Camargo, Nuno Ramos, Rosângela Rennó e Maria Bonomi.

Na curadoria da exposição "Trajetória da luz na arte brasileira", Herkenhoff partiu do séc. XIX, com a vinda da Missão Artística Francesa, e

${ }^{16}$ Ver catálogo Dobras do Corpo Marcas da Alma. Curitiba: Fundação Cultural de Curitiba e Petrobrás, 2000.

${ }^{17}$ Referência ao texto de Hélio Oiticica, "O herói anti-herói e o anti-herói anônimo" (fotocópia de texto paginado, remetido ao crítico Frederico Morais e datado de $25 / 3 / 68$, p. 1) que posteriormente realizaria sua obra "Bólide caixa 18, Poema caixa 2, Homenagem a Cara de Cavalo", outra referência de Paulo Herkenhoff para a exposição. 
chegou até a contemporaneidade, tendo a diafaneidade da representação e do fenômeno da luz como amarração conceitual densa ${ }^{18}$. A luz na História da Arte ligou-se a diferentes visões de mundo, mais idealistas ou mais objetivas e a ações de cunho alegórico ou de acionamento direto da realidade. No Brasil, a trajetória da luz na arte demarcou momentos distintos da cultura, desde a chegada da Missão Francesa, a objetividade do olhar impressionista, o modernismo e a identidade nacional, um projeto de vanguarda comprometida ou as múltiplas pesquisas da contemporaneidade.

A exposição "Tomie Ohtake na trama espiritual da arte brasileira"19 trouxe a obra da artista como o 'locus' de diversas discussões artísticas e culturais do Brasil. Ao afirmar que os lugares de Tomie Ohtake na trama espiritual da arte brasileira implicam aproximar-se da pluralidade cultural do país e revisitar determinadas discussões de diferenças no interior da cultura $^{20}$, o curador evidencia a presença destas coordenadas na obra de Tomie. Algumas indicações destas possibilidades são dadas pela própria trajetória da artista na constituição de sua trama poética, no universo produtivo de sua casa e ateliê e nas peças e objetos artísticos de sua coleção. A exposição dividia-se nos segmentos "Dobras da alma”, "Ultrametafísica”, "Xabori”, "Estética da vida”, "Asè”, “Do Jabaquara ao Brooklin”, "Quieta non movere" e "O impronunciável".

O curador propôs uma outra linha de pensamento para a arte nacional ao substituir um pensamento mais racionalista, que tem como base o projeto construtivo nacional, por um mais espiritualista. Esta questão, presente nos diversos segmentos da mostra, deve ser entendida

${ }_{18}$ Texto do curador em www.itaucultural.org.br/trajetoria_luz/curador00htm (acessado em 29/10/2005)

${ }^{19}$ Museu Oscar Niemeyer, abril a julho de 2004.

${ }^{20}$ Catálogo Tomie Ohtake e a trama espiritual da arte brasileira. Curitiba: Museu Oscar Niemeyer, 2004, p. 51. 
em algumas circunstâncias específicas. Primeiramente na referência, citada pelo curador, da exposição "The spiritual in art: abstract painting 1890-1985"21 que discorria sobre a trajetória de certa modernidade das artes visuais, construída sobre bases metafísicas, como nas operações plásticas de Mondrian, Malevitch e Kandinsky, por exemplo. Além disto, a fundamentação do curador dava-se nas questões filosóficas da metafísica e aquelas ligadas às religiões afro-brasileiras, judaicas, islâmicas, indígenas e ao zen budismo.

As poéticas ligadas à abstração informal ainda não adquiriram um lugar definido na trajetória da arte brasileira. Talvez este fato se dê por uma impossibilidade de se delimitar uma movimentação de caráter informal e subjetivo ou talvez pelo peso histórico ainda decorrente da crítica mais comprometida dos anos 60 . Em função do projeto de vanguarda dos anos 60, alijava-se a abstração informal da discussão mais séria da arte brasileira. A afirmação do viés metafísico e expressivo na arte brasileira construiu um lugar na História da Arte nacional para as poéticas abstratas informais.

Como já realizado nos textos "Incomplete glossary of sources of Latin América” e "Tiempo fracturado" e nas exposições XXIV Bienal de São Paulo (Antropofagia), Mostra da Gravura de Curitiba (Vigiar e Punir) e Trajetória da luz, Herkenhoff trouxe para a Exposição Tomie Ohtake na trama espiritual da arte brasileira seu olhar enciclopédico sobre a arte e suas questões culturais. Alguns segmentos da exposição tocam de perto elementos fundos da discussão cultural e artística do Brasil.

O segmento "Dobras da alma" relaciona-se ao Barroco brasileiro, visto como questão da cultura e como poética plástica ${ }^{22}$. O Barroco

${ }^{21}$ Ocorreu no ano de 1986 no Museu de Arte de Los Angeles.

22 Discussão presente na XII Mostra da Gravura de Curitiba. 
acompanha importantes discussões da cultura brasileira desde o séc. XIX com o estudo biográfico de artistas barrocos (Leandro Joaquim, Frei Ricardo do Pilar) por Araújo Porto-Alegre, passando pela sua afirmação como fundação de identidade artística nacional pelo modernismo brasileiro (após a viagem do grupo modernista paulista e Blaise Cendrars por Minas Gerais) ou como questão decisiva para o equacionamento afirmativo da cultura brasileira, juntamente com a noção de antropofagia ${ }^{23}$. Os artistas que dialogavam com Tomie Ohtake neste segmento eram Aleijadinho, Tarsila do Amaral, Geraldo Leão, Guignard, Leonilson, Dudi Maia Rosa, Adriana Varejão, Oscar Niemeyer, Orlando Azevedo e Rossana Guimarães.

Os segmentos "Xabori” (Xamã), "Asè” e “Do Jabaquara ao Brooklin" retomavam uma discussão ampla e multifacetada do campo da cultura. "Xabori" apresentou representações distintas das culturas indígenas na arte brasileira. $\mathrm{O}$ corte transversal que liga a obra de Tomie às culturas indígenas deu-se em sua participação no projeto do artista Benê Fonteles $^{24}$. Os artistas do segmento eram Orlando Wakatautheri, Benê Fonteles, Claudia Andujar e objetos artísticos Yanomami e Kaiapó. Em "Asè" foi trazida a discussão da representação das culturas africanas no Brasil. Seus artistas eram Emanoel Araújo, Lasar Segall, Antonio Maia, Manuel Messias, Mario Cravo Neto, Mário Cravo Júnior, Ronaldo Rego, Rubem Valentim, o antropólogo Pierre Verger, e uma máscara cerimonial africana. E “Do Jabaquara ao Brooklin” traçou-se um painel dos artistas

${ }^{23}$ Cam 06 italico pos, Haroldo. "O seqüestro do barroco na formação da literatura brasileira: o caso Gregório de Mattos”. Salvador: Fundação Casa de Jorge Amado, 1989.

${ }^{24}$ Em 1990, Fonteles funde idéias do estatuto do artista como xamã e agente político ao convocar colegas para uma exposição organizada a partir de um pequeno objeto de madeira, muito rígido e perfurante. Trata-se de uma ponta de madeira torneada com instrumento feito de dente de cotia por alguns grupos indigenas. Cada estrepe era uma armadilha. Era fincado em grade quantidade nas estradas, confundindo-se com a cor da terra, para furar pneus de veículos de invasores das terras indigenas (cat. "Tomie Ohtake na trama espiritual da arte brasileira”, p.57). 
japoneses no Brasil e as relações da filosofia zen e certa produção artística de época. Seus artistas eram Flávio Shiró, Massao Okinaka, Kazuo Wakabayashi, Hilda Tagusagawa, Kimi Nii, Manabu Mabe, Mauro Fuke, Tmoshige Kusuno e Yozo Hamagushi.

O segmento final da exposição e catálogo “O impronunciável” propôs uma linha de pensamento sobre os limites da linguagem perante 0 fenômeno do divino (transcendência); estabelece-se uma discussão sobre representação visual e linguagem. Seus artistas eram Mira Schendel, Amélia Toledo, Helena Wong, Anatol Wladyslaw, Jac Leirner, Larissa Franco e Tony Camargo.

Espero ter demonstrado neste breve percurso da construção do espaço das exposições e de algumas curadorias de Paulo Herkenhoff como se constitui este lugar privilegiado de proposição artística e construção e reconstrução de algumas questões fundamentais da cultura brasileira. 